\title{
PKM PENERAPAN RUMPON RAMAH LINGKUNGAN BERBASIS MASYARAKAT DI MASA PANDEMI COVID-19 DI KABUPATEN KONAWE SELATAN PROVINSI SULAWESI TENGGARA
}

\section{PKM APPLICATION OF AN ENVIRONMENTALLY FRIENDLY FADS ON COMMUNITY BASED DURING THE PANDEMIC SITUATION OF COVID-19 IN SOUTH KONAWE SOUTHEAST SULAWESI}

\author{
La Ode Abdul Rajab Nadia1*, Salwiyah¹, Abdullah², Amadhan Takwir³, Laode Muhamad \\ Hazairin $\mathrm{Nadia}^{4}$ \\ ${ }_{1}^{1}$ Program Studi Manajemen Sumberdaya Perairan Fakultas Perikanan dan IImu Kelautan Universitas Halu Oleo \\ 2Program Studi Perikanan Tangkap Fakultas Perikanan dan IImu Kelautan Universitas Halu Oleo \\ 3Program Studi IImu Kelautan Fakultas Perikanan dan IImu Kelautan Universitas Halu Oleo \\ ${ }^{4}$ Program Studi Teknologi Hasil Perikanan Fakultas Perikanan dan Ilmu Kelautan Universitas Halu Oleo \\ *Korespondensi : rajabnadiauho@gmail.com / Mobile : +6281342627874
}

\begin{abstract}
ABSTRAK
Masalah utama yang dihadapi nelayan di Desa Wawatu dalam kegiatan produksi perikanan tangkap adalah daerah fishing ground ikan terbatas akibat kegiatan penangkapan ikan tidak ramah lingkungan, daerah spawning dan nursery belum tertata dan dikelola dengan baik, sehingga ketersediaan stok ikan di habitatnya belum mencukupi kebutuhan nelayan dan pelaku usaha perikanan tradisional. Kegiatan pengabdian ini bertujuan untuk lebih mengoptimalkan fungsi rumpon sebagai alat bantu penangkapan ikan, memikat cumi dan kepiting rajungan untuk berkumpul di area rumpon. Kegiatan PKM ini diharapkan dapat menjadi salah satu solusi untuk meningkatkan produksi pangan ikan di masa pandemi COVID-19 di Desa Wawatu Kecamatan Moramo Utara Kabupaten Konawe Selatan. Kegiatan pengabdian masyarakat ini dilaksanakan dengan 2 pendekatan yaitu pendekatan pelatihan partisipatif pada mitra dan aplikasi teknologi di lokasi demplot. Hasil dari kegiatan pengabdian ini adalah masyarakat cukup antusias dalam mengikuti seluruh kegiatan mencakup kegiatan pelatihan dan diskusi serta penerapan teknologi rumpon ramah lingkungan, mencakup partisipasi aktif dalam persiapan bahan, pembuatan rumpon dan pemasangan rumpon di perairan.
\end{abstract}

Katakunci : Pangan Ikan, Rumpon, Ramah Lingkungan, Wawatu

\begin{abstract}
The major problem in fishing production activities faced by fishermen in Wawatu Village is the limited fishing ground area caused by unfriendly-environmentally fishing activities, unorganized spawning and nursery areas so that the availability of fish stocks in their habitats is insufficient for fishermen and traditional fishery businesses. The main focus of this community dedication activity was to further optimize FADs functions as a fishing tool, attracting squid and crabs to gather inside the FADs area. This activity can be one of the solutions to increase fish production during the COVID-19 pandemic in Wawatu Village, North Moramo District, South Konawe Regency. There were two approaches in this activity, namely 1) approach of participatory training to partners, 2) technology applications at the demonstration plot (demplot) location. The result showed that the community was quite enthusiastic in participating in all activities including training and discussion activities as well as the application of environmentally friendly FADs technology, including active participation in material preparation, making of FADs and installing FADs in the water.
\end{abstract}

Keyword : Fish food, Environmentally friendly, FADs, Wawatu 


\section{PENDAHULUAN}

Desa Wawatu merupakan salah satu desa pesisir yang berada di Kecamatan Moramo Utara, Kabupaten Konawe Selatan. Secara administrasi, desa tersebut memiliki luas wilayah $22,5 \mathrm{~km}^{2}$ dengan jumlah penduduk sebanyak 1456 jiwa (BPS, 2020). Sebagai daerah pesisir, Desa Wawatu memiliki potensi sumberdaya perikanan dan kelautan baik perikanan tangkap maupun perikanan budidaya. Hal tersebut menjadikan masyarakat yang bermukim di desa tersebut memiliki matapencaharian sebagai nelayan tradisional.

Saat ini, masalah utama yang dihadapi nelayan di Desa Wawatu dalam kegiatan produksi perikanan tangkap adalah daerah fishing ground ikan terbatas akibat kegiatan penangkapan ikan tidak ramah lingkungan, daerah spawning dan nursery belum tertata dan dikelola dengan baik, sehingga ketersediaan stok ikan di habitatnya belum mencukupi kebutuhan nelayan dan pelaku usaha perikanan tradisional. Selain itu, jumlah hasil tangkapan ikan, cumi-cumi dan kepiting rajungan cenderung fluktuatif, sehingga usaha nelayan cenderung stagnan dan susah untuk berkembang. Selanjutnya, keterbatasan teknologi yang dimiliki nelayan mitra untuk meningkatkan produksi perikanan tangkap berkelanjutan menjadi masalah serius yang belum tuntas sampai sekarang ini.

Pendekatan masalah yang solutif dan strategis adalah penerapan produk teknologi rumpon ramah lingkungan ke masyarakat. Rumpon atau fish Agregation Device merupakan suatu alat bantu penangkapan ikan yang telah banyak digunakan oleh nelayan karena dapat meningkatkan produksi hasil tangkapan dan mengurangi destruktif fishing (Nadia, dkk., 2016; Nadia, dkk., 2018; Kurniawan, dkk., 2013). Produk teknologi yang diterapkan ke masyarakat tersebut adalah keterpaduan rumpon cumicumi dan rumpon kepiting rajungan. Kedua rumpon tersebut saling terkoneksi secara ekologis dan fungsinya di perairan.

Hasil inovasi teknologi rumpon ramah lingkungan bertujuan untuk lebih mengoptimalkan fungsi rumpon sebagai alat bantu penangkapan ikan, memikat cumi dan kepiting rajungan untuk berkumpul di area rumpon. Produk teknologi tersebut telah terbukti dan telah dikembangkan dalam skala penelitian, sehingga kesiapan teknologi untuk dideseminasikan ke masyarakat sudah siap pakai. Selanjutnya, kegiatan PKM ini diharapkan dapat menjadi salah satu solusi untuk meningkatkan produksi pangan ikan di masa pandemi COVID-19 di Desa Wawatu Kecamatan Moramo Utara Kabupaten Konawe Selatan.

\section{METODE PELAKSANAAN}

\section{Waktu dan Lokasi}

Kegiatan PKM ini dilaksanakan pada bulan September 2020. Lokasi kegiatan ini adalah desa Wawatu Kecamatan Moramo Utara Kabupaten Konawe Selatan Provinsi Sulawesi Tenggara. 


\section{Metode}

Kegiatan pengabdian masyarakat ini dilaksanakan dengan 2 pendekatan, yaitu pendekatan pelatihan partisipatif pada mitra dan aplikasi teknologi di lokasi demplot. Kegiatan tersebut dilaksanakan dengan tahapan-tahapan sebagai berikut:

1) Sosialisasi kegiatan pada mitra yaitu Kelompok Nelayan Samaturu dan Kelompok Nelayan Wawatu Mandiri di desa Wawatu Kabupaten Konawe Selatan. Sosialisasi program kegiatan ini dilakukan untuk mengenalkan rencana kegiatan pengabdian masyarakat kepada mitra sehingga mitra dapat memahami dengan baik rencana kegiatan pengabdian tersebut. Sosialisasi ini juga dilakukan untuk memperlancar proses pelaksanaan pengabdian. Kegiatan sosialisasi ini diharapkan semua kendala dapat diselesaikan agar pelaksanaan program pengabdian berjalan dengan baik.

2) Pelatihan penguatan kapasitas mitra. Pelatihan terdiri atas pemaparan materi dan diskusi.

3) Penyediaan bahan baku teknologi rumpon ramah lingkungan.

4) Pembuatan rumpon ramah lingkungan, meliputi rumpon cumi dan dan rumpon kepiting rajungan.

5) Pemasangan rumpon di perairan desa Wawatu Kabupaten Konawe Selatan

\section{HASIL DAN PEMBAHASAN}

Pelaksanaan kegiatan PKM rumpon ramah lingkungan berbasis masyarakat telah dilaksanakan sesuai perencanaan awal kegiatan. Kegiatan ini telah mengintroduksikan teknologi rumpon ramah lingkungan ke mitra, mencakup rumpon cumi dan rumpon rajungan. Jumlah rumpon yang telah dihasilkan adalah 2 unit rumpon cumi dan 2 unit rumpon rajungan.

Tahapan pelaksanaan teknis kegiatan terdiri atas 5 tahap, yaitu 1) sosialisasi program; 2) pelatihan penguatan kapasitas masyarakat dan bimbingan teknis pembuatan rumpon; 3) pelaksanaan pembuatan rumpon; 4) pelaksanaan pemasangan rumpon di perairan. Capaian hasil tersebut mencakup kegiatan teknis dan non teknis.

Keluaran capaian kegiatan terwujud dengan tahapan kegiatan sebagai berikut:

\section{1) Sosialisasi Program}

Kegiatan sosialisasi mencakup: koordinasi dengan Kepala Desa Wawatu dan sosialisasi kepada masyarakat sasaran. Kegiatan tahap awal bertujuan untuk memperoleh dukungan semua pihak terkait dengan rencana pelaksanaan kegiatan PKM rumpon ramah lingkungan berbasis masyarakat di masa pandemi COVID-19. Hasil koordinasi tersebut telah memperoleh beberapa kesepakatan yaitu: a) Kepala Desa Wawatu mendukung sepenuhnya program PKM ini dan menfasilitasi pertemuan dengan mitra kelompok nelayan; b) Kepala Desa Wawatu berkewajiban untuk melakukan monitoring kegiatan Kelompok Nelayan sehingga seluruh anggota kelompok dapat berpartisipasi aktif dalam kegiatan; 3) Kepala Desa Wawatu dapat berperan sebagai kontrol program di lapangan sehingga teknologi yang dikembangkan tim PKM Universitas Halu Oleo dapat mencapai sasaran. Kegiatan sosialisasi program disajikan pada Gambar 1. 


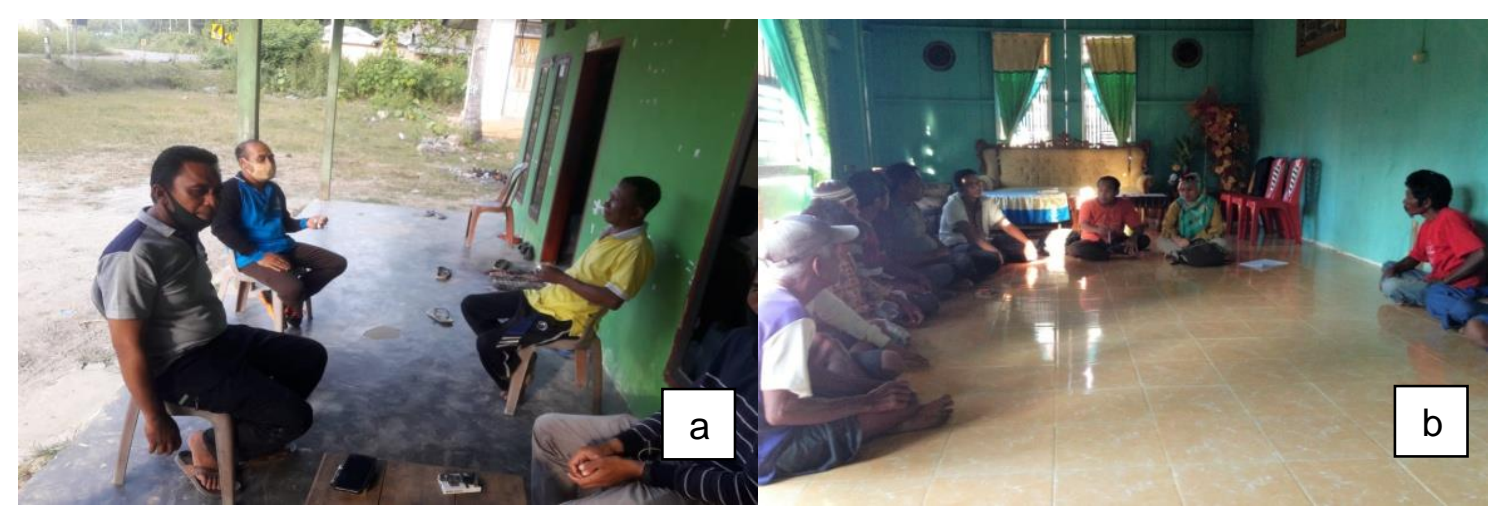

Gambar 1. Sosialisasi program: a) koordinasi dengan kepala desa, b) pertemuan dengan kelompok nelayan

Kegiatan sosialisasi mendapat respon yang sangat baik dari pemerintah desa dan seluruh anggota Kelompok Nelayan. Hal tersebut terkait dengan manfaat kegiatan pengabdian yang dianggap sangat berdampak bagi nelayan. Selain itu, fungsi teknologi rumpon ramah lingkungan dinilai nelayan sebagai salah satu sumber solusi atas permasalahan utama yang dihadapi nelayan saat ini, yaitu menurunnya produktivitas hasil tangkapan ikan di laut dan semakin jauh daerah fishing ground, dapat berkontribusi untuk meningkatkan produktivitas usaha kelompok nelayan dan juga meningkatkan pendapatan masyarakat di desa Wawatu Kabupaten Konawe Selatan.

\section{2) Pelatihan penguatan kapasitas Kelompok Nelayan}

Pelatihan penguatan kapasitas Kelompok Nelayan bertujuan untuk meningkatkan pemahaman masyarakat mencakup aspek kelembagaan dan usaha kreatif, aspek teknis teknologi rumpon ramah lingkungan, pengelolaan rumpon dan penguatan skill mitra dalam pengelolaan produk teknologi. Pelatihan ini dilakukan secara formal di Aula Balai Desa Wawatu Pemerintah desa.

Materi tentang pengelolaan kelembagaan dan penguatan usaha kreatif menitikberatkan pada aspek penguatan kelembagaan Keleompok Nelayan yang mencakup manajemen kelembagaan, model pengelolaan kelembagaan partisipatif, peran kelembagaan dalam pengelolaan rumpon ramah lingkungan serta pengelolaan usaha perikanan tangkap secara tepat, terpadu dn berkelanjutan. Materi ini sangat penting bagi penguatan kelembagaan mitra karena berorientasi pada pengelolaan usaha berbasis kelompok.

Selanjutnya, materi aspek teknis teknolog rumpon ramah lingkungan lebih difikuskan pada fungsi teknologi, teknis pembuatan teknologi, pemasangan teknologi di perairan dan pengelolaan teknologi sebagai alat bantu produksi ikan selama masa pandemi COVID-19. Penyampaian materi dilakukan 2 tahap, yaitu tahap 1 dilaksanakan di Aula Balai Desa Wawatu pada hari pertama kegiatan dan tahap kedua dilaksanakan di Sekretariat Kelompok Nelayan. Kegiatan pelatihan mitra PKM disajikan pada Gambar 2. 


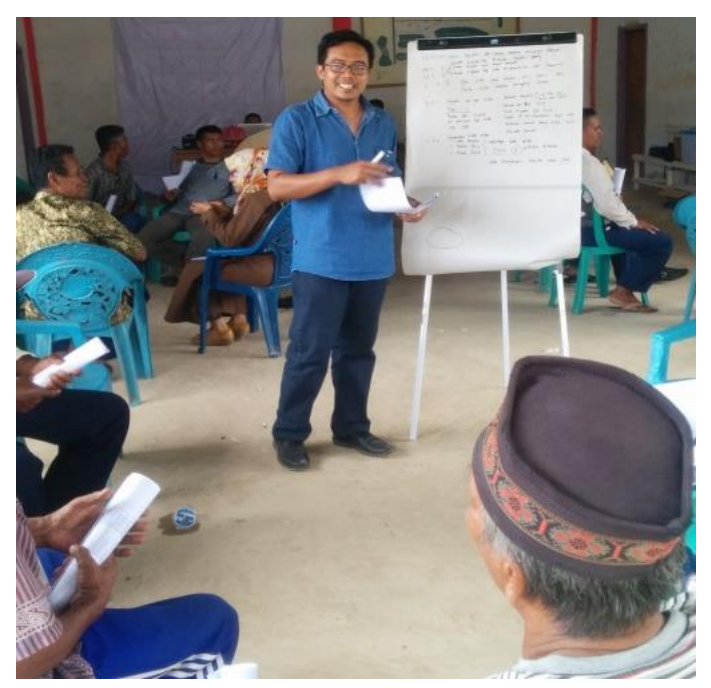

Gambar 2. Kegiatan pelatihan PKM

Untuk memperkuat kapasitas sumberdaya manusia seluruh anggota Kelompok Nelayan, salah satu strategi yang penting adalah kemitraan berbasis teknologi produktif. Untuk membentuk kemitraan-kemitraan ini, peranan pemerintah dan instansiinstansi pendukung lainnya sangat dibutuhkan. Peranan pemerintah dapat dilakukan melalui penciptaan iklim usaha yang kondusif berbasis kemitraan dan dapat pula memberikan fasilitas dan dukungan-dukungan lain seperti misalnya fasilitas penciptaan keserasian (match making), menyediakan bantuan keuangan, menyediakan fasilitas teknologi tepat guna dan keperluan-keperluan yang lainnya untuk menjembatani kemitraan antara kedua pihak tersebut.

Berangkat dari berbagai masalah yang dihadapi kelompok mitra, maka dalam pengembangan organisasi nelayan harus berorientasi pada beberapa hal:

1. Mengembangkan usaha kelompok nelayan yang diarahkan untuk memberikan kontribusi yang signifikan terhadap peningkatan pendapatan pada kelompok masyarakat berpendapatan rendah, penciptaan lapangan kerja, dan peningkatan daya saing produk kelompok nelayan.

2. Memperkuat kelembagaan dengan menerapkan prinsip-prinsip tata organisasi kelompok produktif dengan mengedepankan gender atau partisipasi perempuan dari ibu-ibu nelayan sebagai lokomosi usaha kreatif di desa Puasana dalam pengelolaan ikan pasca tangkap di rumpon terpadu dengan memperluas akses kepada sumber permodalan melalui BUMDES (Badan Usaha Milik Desa), koperasi yang sehat dan perbankan, memperbaiki lingkungan usaha dan usaha kreatif mitra dengan izin usaha.

3. Mengembangkan usaha kelompok nelayan melalui pendekatan klaster hilirisasi produk multi varian di sektor agribisnis perikanan.

Materi pelatihan penerapan rumpon ramah lingkungan pada masyarakat disampaikan dalam bentuk pemaparan materi dan diskusi. Isi materi adalah teknis pembuatan teknologi, pemasangan teknologi di laut, pengelolaan teknologi berkelanjutan serta pengawasan teknologi. Kegiatan pelatihan teknis teknologi rumpon ramah lingkungan disajikan pada Gambar 3. 


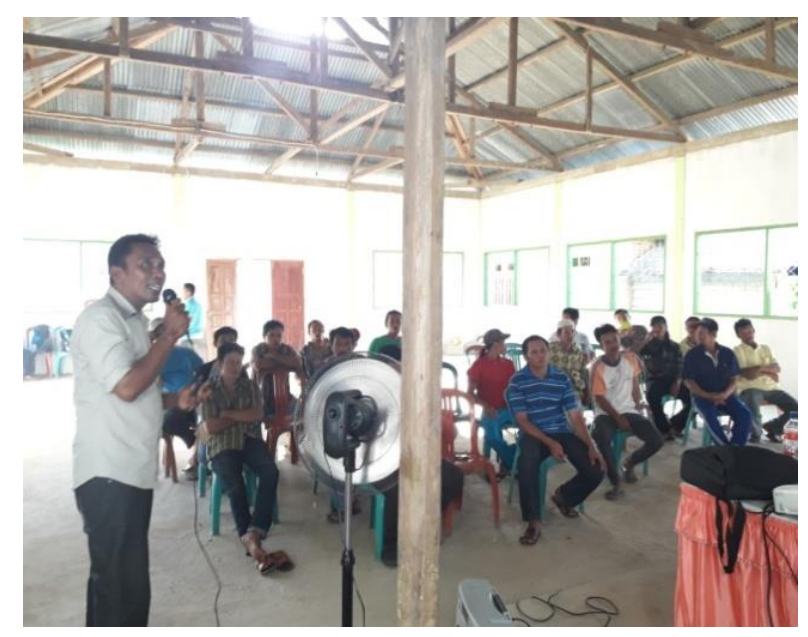

Gambar 3. Kegiatan pelatihan tentang rumpon ramah lingkungan

Point penting yang disampaikan pemateri pada kegiatan pelatihan penerapan rumpon ramah lingkungan adalah:

1. Pemateri memberikan penguatan kepada peserta tentang fungsi rumpon dalam pengelolaan sumberdaya ikan di Desa Wawatu, fungsi rumpon dalam memikat ikan/cumi/kepiting rajungan, menghimpun ikan serta tempat naungan bagi ikan. Selanjutnya, rumpon berfungsi sebagai tempat pelekatan telur cumi, naungan induk cumi dan juga tempat ikan mencari makan karena terdapat plankton dan lumut pada shelter dan rakit rumpon. Plankton adalah makanan alami bagi ikan kecil dan biota laut lainnya (Munirma, dkk., 2020). Kondisi demikian akan terjadi berkesinambungan karena siklus makanan terjadi di rumpon. Dalam kurun waktu tertentu, rumpon mampu menyediakan stok cumicumi/ikan/kepiting rajungan untuk dioptimalkan nelayan setempat. Hal tersebut sangat penting disampaikan agar dalam implementasi teknologi, Kelompok Nelayan berkewajiban untuk mengelola rumpon dengan memperhatikan aspek penggunaan alat tangkap yang ramah lingkungan, pengawasan rumpon dan pemeliharaan rumpon secara partisipatif. Diharapkan keberadaan rumpon berkontribusi kepada peningkatan pendapatan nelayan.

2. Pemateri menyampaikan materi teknis pembuatan rumpon ramah lingkungan (rumpon cumi/ikan dan rumpon rajungan) yang mencakup bahan-bahan rumpon, desain rumpon, cara pembuatan, pemasangan rumpon dan pemeliharan rumpon. Hal yang paling utama untuk ketahanan rumpon adalah jenis bambu yang akan digunakan untuk rakit rumpon rajungan dan bahan batang asam jawa untuk rumpon cumi.

Setelah pemaparan materi, moderator memandu kegiatan pelatihan dengan diskusi kelompok. Dalam diskusi tersebut, moderator mengarahkan peserta untuk lebih menggali informasi tentang aspek teknis pembuatan rumpon dan pembagian kerja Kelompok Nelayan dalam pembuatan rumpon. Diskusi kelompok berjalan lancar, informasi yang dihasilkan dalam diskusi bukan hanya diperoleh dari pemateri tetapi juga berasal dari peserta. Dalam diskusi terjadi sharing informasi terkait dengan penguatan desain dan teknik pembuatan rumpon. Hal tersebut disampaikan nelayan berdasarkan pengalaman mereka dalam membuat rumpon dan penangkap ikan di rumpon pada daerah lain. 


\section{3) Pembuatan Rumpon Ramah Lingkungan}

Rumpon merupakan salah satu alternatif yang cukup efektif dalam mengumpulkan ikan/cumi/kepiting rajungan. Agar rumpon dapat bertahan lama dan berfungsi untuk memikat sumberdaya ikan, maka pembuatan rumpon dilaksanakan secara bertahap yang terdiri atas 3 bagian utama, yaitu jangkar, rakit dan pelampung. Jangkar harus kuat karena sebagai kekuatan utama rumpon di perairan yang menahan tekanan arus bawah sehingga rumpon tetap kokoh pada tempatnya. Rakit rumpon cumi dibuat secara bersusun dan terbuat dari bahan batang asam (Nadia, dkk., 2016).

Kegiatan pembuatan rumpon mendapat respon yang baik dari masyarakat. Antusias masyarakat terlihat dari persiapan bahan rumpon hingga pembuatan rumpon. Masyarakat beranggapan bahwa keterlibatannya dalam kegiatan pembuatan rumpon disebabkan adanya keingintahuan terhadap teknologi yang diterapkan tim PKM Universtas Halu Oleo dan juga adanya keinginan untuk saling berbagi pengalaman dalam pembuatan rumpon.

a) Pembuatan rumpon cumi

Tahapan pembuatan rumpon cumi sebagai berikut:

1. Membuat jangkar

Tim pelaksana mempersiapkan bahan dan peralatan pembuatan jangkar. Dalam pelaksanaannya, masyarakat terlibat dalam proses kerja jangkar rumpon. Tahapan pembuatan jangkar rumpon cumi sama dengan tahapan pembuatan rumpon ikan. Jangkar pemberat rumpon cumi dibuat menggunakan semen cor dengan ukuran $40 \mathrm{~cm}$ x $50 \mathrm{~cm}$ dengan penulangan besi 8 inci. Didalam jangkar/semen cor tersebut diliitkan tali nilon ukuran $18 \mathrm{~mm}$ sebagai simpul pengikat tali rumpon yang menghubungkannya dengan pelampung di permukaan air. Berat jangkar ini diperkirakan mencapai $200-250 \mathrm{~kg}$. Waktu yang dibutuhkan dalam pembuatan jangkar rumpon adalah 10 hari sampai kondisinya betul-betul kering.

2. Merakit batang pohon asam secara berderet yang dikombinasikan dengan bambu

Tim pelaksana dan anggota kelompok nelayan bersama-sama membuat rakit rumpon cumi. Dalam pelaksanaannya, mitra PKM baru mengetahui kalau bahan untuk membuat rumpon cumi adalah batang asam. Rakit batang asam dibuat bersusun. Setiap rumpon menggunakan 2 rakit bersusun secara vertikal dan jumlah rumpon cumi yang dihasilkan sebanyak 2 unit. .

3. Membungkus drum gabus dengan jaring

Proses pembuatan pelampung rumpon cumi sama dengan pembuatan pelampung rumpon ikan. Pelampung yang diguanakan adalah drum gabus. Bahan ini berfungsi sebagai pelampung rumpon. Pelampung yang digunakan setiap rumpon sebanyak 1 buah. Sebelum pemasangan rumpon, batang asam yang sudah dirakit tersebut disayat sehingga memunculkan aroma khas batang asam. Aroma inilah yang memikat cumi untuk berkumpul di sekitar rumpon. Dokumentasi rakit rumpon cumi disajikan pada Gambar 4 dan jangkar rumpon cumi Gambar 5. 


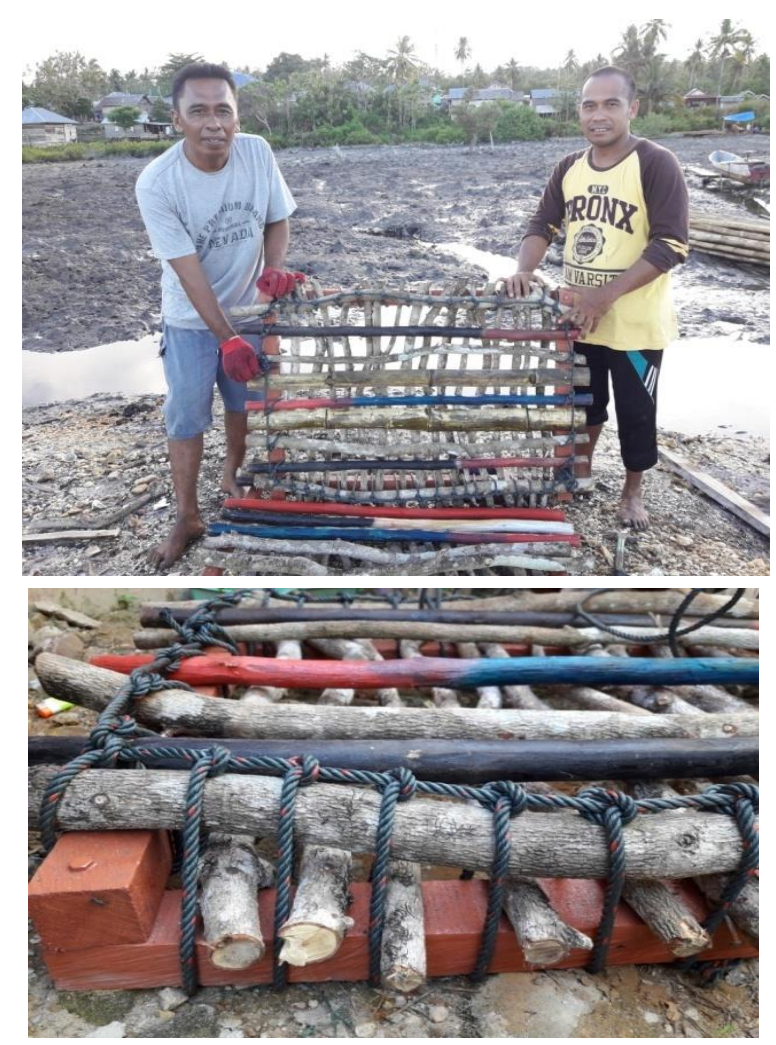

Gambar 4. Salah satu rakit rumpon cumi

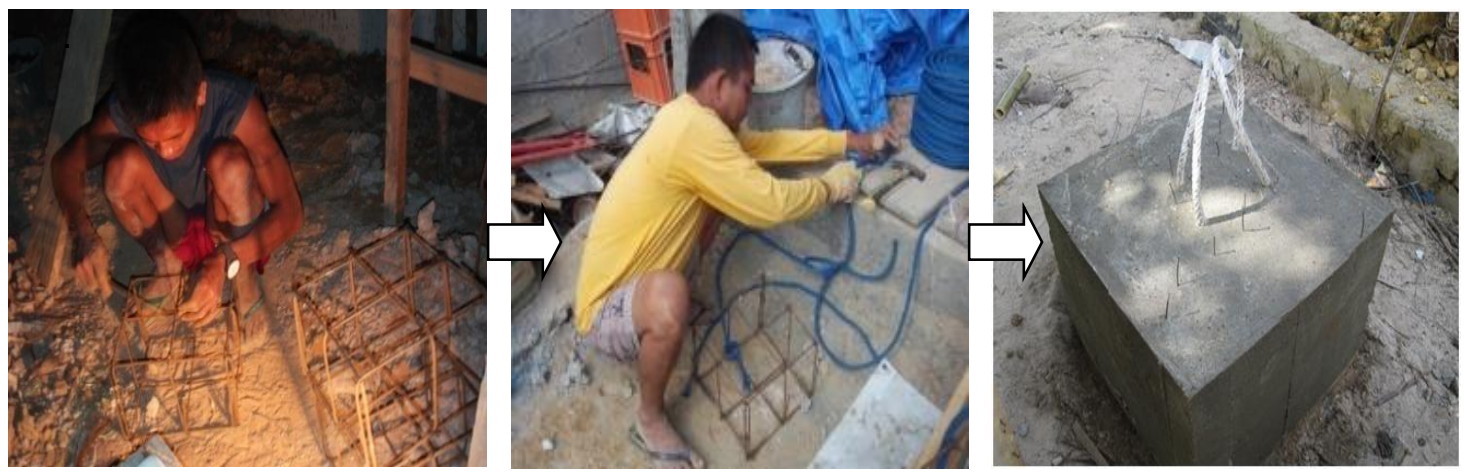

Gambar 5. Proses pembuatan jangkar/pemberat rumpon cumi

4. Pembuatan rumpon rajungan Kegiatan pembuatan rumpon rajungan di Desa Wawatu sebagai berikut:

5. Membuat jangkar Jangkar rumpon rajungan terbuat dari cor beton dengan ukuran $20 \times 30 \mathrm{~cm}$. Jangkar rumpon berbentuk segi empat, sehingga sangat membantu untuk stabilisasi rumpon di air.

6. Mendesain rumpon rajungan

Rumpon rajungan dibuat berbentuk piramida dan bahan yang digunakan adalah bambu. Setiap simpul pada rumpon menggunkan tali ukuran $6 \mathrm{~mm}$. Pada bagian dasar rumpon dibuat empat persegi dan terdapat lantai rumpon untuk tempat meletakan shelter dan bagian sisi rumpon diletakkan umbai-umbai dari daun kelapa. Kegiatan pembuatan rumpon rajungan disajikan pada Gambar 6 dan Gambar 7. 


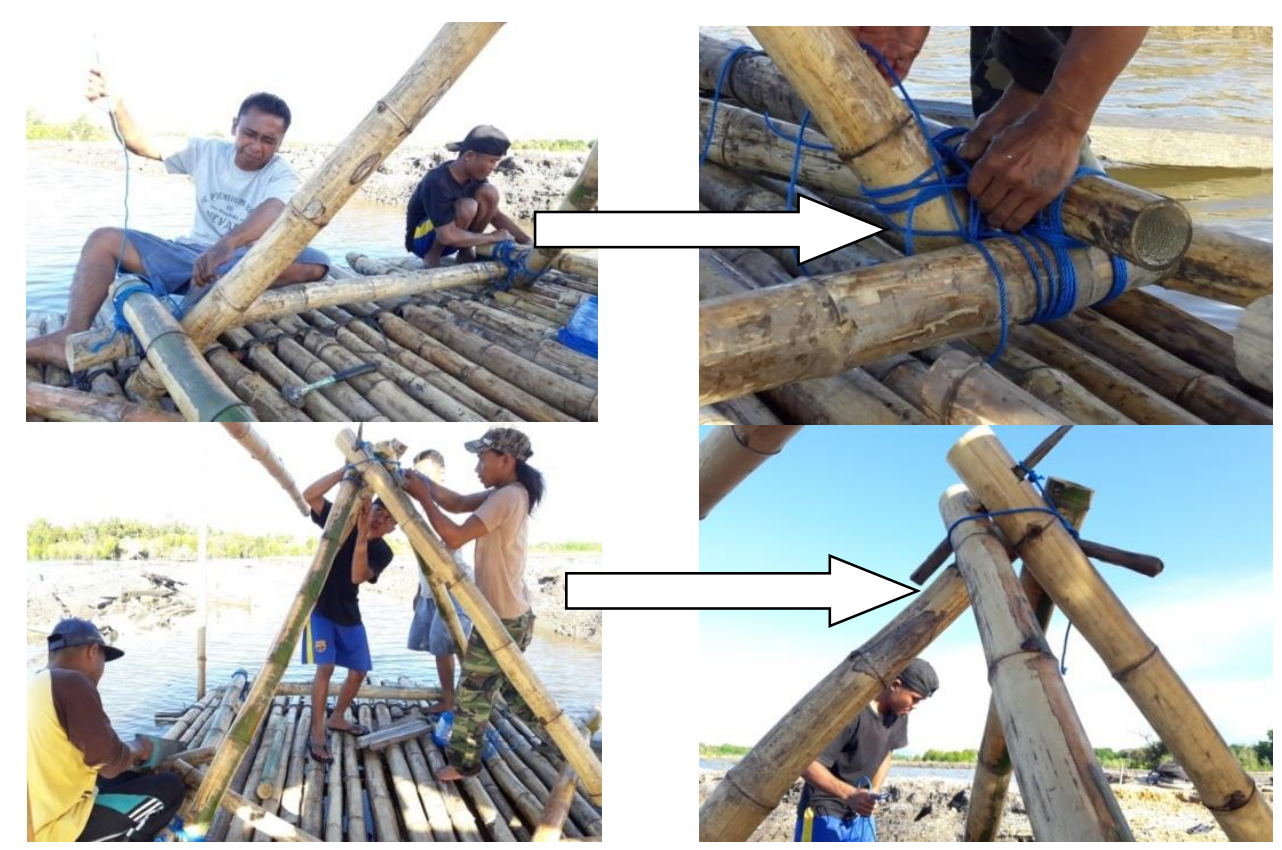

Gambar 6. Proses pengikatan rumpon rajungan

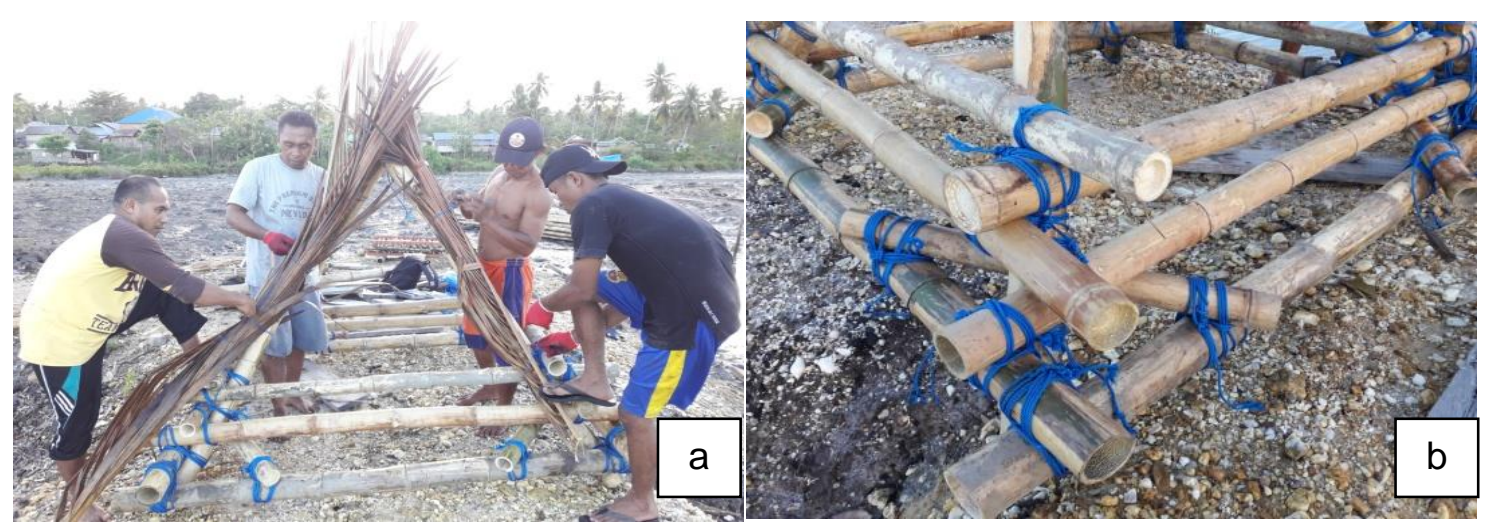

Gambar 7. Susunan konstruksi rumpon rajungan: a) penampilan rumpon secara keseluruhan, b) bagian sisi dasar rumpon rajungan

\section{4) Pemasangan rumpon di perairan}

Kegiatan pemasangan rumpon dilaksanakan tim PKM Universitas Halu Oleo bersama anggota kelompok nelayan. Masyarakat sangat antusias dalam kegiatan tersebut terutama dalam pengangkutan rumpon menggunakan rakit bambu. Kegiatan pemasangan rumpon diawali dengan pengangkutan bahan-bahan rumpon seperti tali, pemberat dan pelampung. Untuk memudahkan mobilisasi bahan-bahan tersebut, maka jangkar rumpon ditempatkan di atas rakit bambu dan ditarik dengan perahu motor (katinting) ke lokasi pemasangan rumpon.

Pemasangan rumpon cumi diawali dengan menghubungkan jangkar dengan pelampung menggunakan tali rumpon. Panjang tali rumpon 2 kali kedalaman perairan. Tujuannya untuk dijadikan sebagai lanjar agar rumpon tidak mudah putus dan terbawa arus. Selanjutnya, tali tersebut dibentangkan di sepanjang perairan mengikuti arah arus yang bertujuan agar pada saat menurunkan jangkar/pemberat, tali yang dihubungkan dengan pelampung tidak tersangkut pada perahu. Pada saat tali jangkar 
selesai dibentangkan, ujung tali diikat pada pelampung gabus dan selanjutnya jangkar didorong ke laut dan secara bersamaan pelampung dilepas di perairan.

Selanjutnya, rumpon rajungan diletakkan di sekitar habitat keiting rajungan. Material rumpon rajungan dibawa di perairan dengan menggunakan perahu bermotor. Saat berada di lokasi, rumpon diletakkan di perairan. Agar memudahkan rumpon tenggelam, maka diberikan pemberat dari cor beton. Penurunan rumpon cumi dan rumpon rajungan disajikan pada Gambar 8.

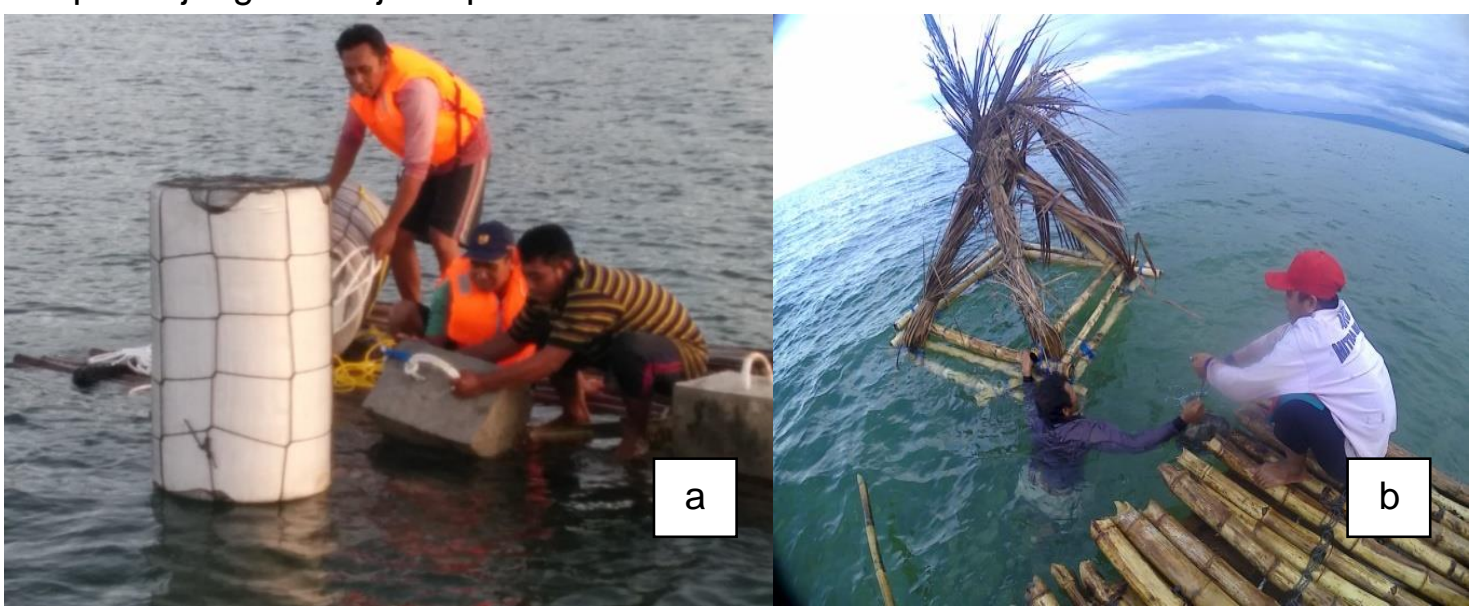

Gambar 8 . Pemasangan rumpon: a) rumpon cumi; b) rumpon rajungan

\section{SIMPULAN}

Berdasarkan hasil dan pembahasan maka dapat disimpulkan bahwa partisipasi masyarakat dalam penerapan rumpon ramah lingkungan di Desa Wawatu Kecamatan Moramo Utara Kabupaten Konawe Selatan sangat tinggi. Masyarakat langsung dapat mengadopsi teknologi karena adanya pemahaman teknologi yang diperoleh melalui kegiatan pelatihan partisipatif dan demplot teknologi yang melibatkan partisipasi masyarakat secara langsung. Pembuatan dan pemasangan rumpon ramah lingkungan dapat terealisasi sesuai dengan perencanaan. PKM ini telah mampu meningkatkan sumber daya manusia dan aspek teknis operasional teknologi. Dengan pelatihan tersebut, mitra PKM mempunyai pengetahuan untuk mengoperasikan dan mengelola rumpon untuk peningkatan produksi pangan ikan.

\section{UCAPAN TERIMA KASIH}

Terima kasih kepada Bapak Rektor Universitas Halu Oleo dan Ketua LPPM Universitas Halu Oleo yang telah menfasilitasi pendanaan kegiatan Pengabdian Masyarakat Internal Universitas Halu Oleo. Selanjutnya, terima kasih pula kepada Kepala Desa Wawatu yang berkontribusi besar dalam kesuksesan pelaksanaan kegiatan pengabdian di Desa Wawatu. Semoga usaha bersama ini menjadi amal ibadah.

\section{DAFTAR PUSTAKA}

BPS, 2020. Kecamatan Moramo Utara dalam Angka. Konawe Selatan. Sulawesi Tenggara. 
Kurniawan, M.R, Setyahadi dan G. Bintoro. 2013. Pengaruh pemasangan rumpon pada musim barat terhadap hasil tangkapan Alat tangkap payang di perairan tuban jawa timur. PSPK Student Journal. 1 (1): 16-20.

Munirma, M. Kasim, N. Irawati, Halili, Salwiyah, LOAR Nadia, 2020. Studi Produktivitas Primer Fitoplankton di Perairan Danau Motonuno Desa Lakarinta Kecamatan Lohia Kabupaten Muna. Jurnal Manajemen Sumberdaya Perairan. 5 (1): 8-16.

Nadia, L.O.A.R., Abdullah, A. Takwir. 2018. Model agromarine berkelanjutan melalui integrasi teknologi karamba jaring apung (kja), rumpon dasar ramah lingkungan dan sero sistem kluster Di Sulawesi Tenggara. Jurna Nasional Teknologi Terapan. 2(2): 132-146.

Nadia, L.O.A.R., Abdullah, A. Takwir, M. Balubi. 2016. Pengelolaan rumpon terpadu berbasis POKJAMAS untukmeningkatkan stok ikan dan penguatan UMKM nelayan. Research Report. 2(1) 168-177. 